\title{
Adaptive Right-Time Technologies in Customer Relationship Management
}

\section{DOI 10.1007/s12599-009-0084-x}

\section{The Authors \\ Dipl.-Kfm. Lukas Grieser \\ Prof. Dr. Klaus D. Wilde \\ Lehrstuhl für $A B W L$ und \\ Wirtschaftsinformatik \\ Katholische Universität \\ Eichstätt-Ingolstadt \\ Auf der Schanz 29 \\ 85049 Ingolstadt \\ Germany \\ lukas.grieser@ku-eichstaett.de \\ klaus.wilde@ku-eichstaett.de \\ url: http://www.wi-ingolstadt.de}

Received: 2009-07-27

Accepted: 2009-11-13

Accepted after two revisions by Prof. Dr. Sinz.

This article is also available in German in print and via http://www. wirtschaftsinformatik.de: Grieser L, Wilde KD (2010) Adaptive-RightTime-Technologien im Customer Relationship Management. WIRTSCHAFTSINFORMATIK. doi: 10.1007/ s11576-009-0208-4.

\section{Out-Dated Decision Basis in CRM}

Customer relationship management $(C R M)$ is highly affected by its dynamic environment. In this context, the symbiotic qualities of adaptability and realtime technologies offer new potentials of process optimization and integration.

CRM is about establishing and maintaining profitable long term customer relationships. It involves the coordination of customer directed business processes in marketing, sales, and service (Hippner and Wilde 2002, pp. 6-8). These processes are typically subject to very rapid changes of customer behavior (e.g. due to seasonality, fashion, tests, etc.) and business environment (e.g. new product launches, special prices, commercials, etc.). The implied dynamics necessitate a continuous adaptation to present market conditions.
In regard to e.g. target group planning for catalogues, mailings or e-mail newsletters, campaign management in CRM always has to consider up-to-date customer needs while bearing in mind ongoing competitor activities and their effect on customer behavior. In practice, however, target groups for the next month $t_{1}$ are planned on the basis of the reaction data of similar campaigns from previous months $t_{-1}, t_{-2}, \ldots, t_{-n}$. The actualization of customer-specific response predictions (which are the analytical foundation of the business rules for target group definition) is carried out in month $t_{0}$. In other words, the actualization is conducted on the basis of out-dated data. In addition, it takes place one month before the actual campaign execution. Accordingly, response prediction for the individual customer does not reflect customer behavior during the campaign execution in month $t_{1}$, but the behavior within the months of provided data $t_{-1}, t_{-2}, \ldots, t_{-n}$ (Berry and Linoff 2000, pp. 206-208). Derived business rules for campaign target groups only insufficiently cover customers with factual strong response probability. Given this diluted decision basis, potential revenues are not realized.

A continuous adaptation of business rules in real-time cuts these losses but involves enhancements, both on the system side and on the process side of traditional operations.

\section{Operational and Analytical Processes in CRM}

Processes in CRM are supported by an operational and an analytical CRMsystem (Hippner et al. 2004, pp. 13-42). In regard to campaign management the operational system particularly serves to synchronize customer directed processes, e.g. the management of a call center cross-selling campaign. Present business rules are applied to customer data which are provided by operational databases. In the majority of cases this process is automated. The call center agent is supplied with new contacts and the corresponding dialog guidelines via an operational interface which captures customer responses and transfers them to connected databases.

Separate from the operational system, the analytical CRM-system supports the development of the operationally applied business rules using Online Analytical Processing (OLAP) and data mining. This manual process is costly in terms of labor and time. Therefore it results in only sporadic adaptations and re-developments of business rules and impedes a continuous adaptation. Moreover, latest operational data for the actualization of business rules is rarely provided due to long synchronization cycles between operational and analytical systems (which is sufficient for a sporadic actualization of business rules, but constraining for realtime adaptation).

The objectives of the application of adaptability and real-time technologies are the integration of operational and analytical processes, resulting in an optimal adjustment of CRM-processes regarding to current customer and market behavior: Recent changes in customer data are perceived, captured, and provided instantly through operational processes supporting the development of analytical components, e.g. an individual customer buying prediction on a daily basis. These components are immediately incorporated in business rules controlling the operational processes, e.g. the selection of customers for a campaign promoting a new mobile tariff the next day. The selection of the target group is therefore based on market information which is only a few days or even just a couple of hours old. It reflects the current market conditions resulting in a higher rate of contracts signed.

\section{Adaptability in CRM-Processes}

Highly competitive markets induce a dynamic environment resulting in a constant change of customer behavior and therefore require adaptability within CRM-processes. Fig. 1 illustrates the 


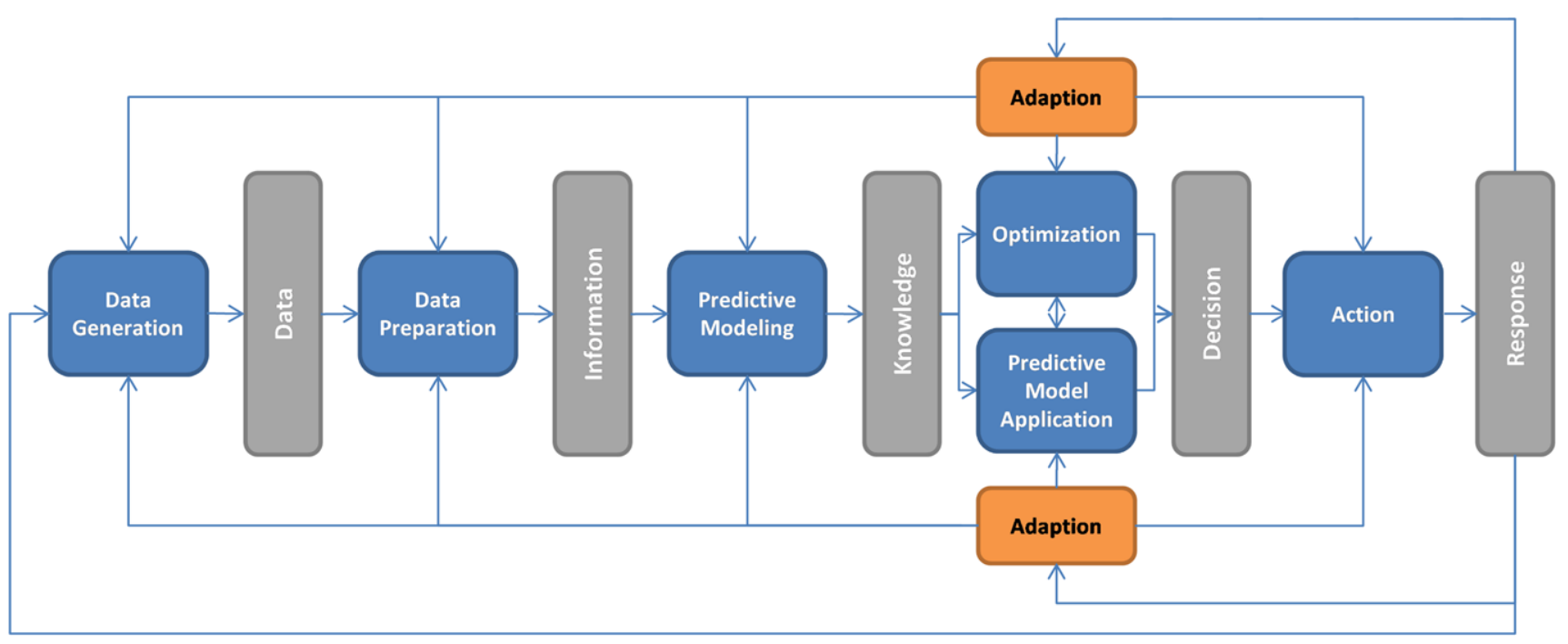

Fig. 1 Adaptive campaign management process (closed-loop)

adaptive process of campaign management (Michalewicz et al. 2007, p. 5). First, transaction and customer data are collected from operational CRMsystems (Data Generation) and are prepared, transformed, and uploaded to corresponding databases (Data Preparation). The data are then available for the development of customer-individual behavior predictions, e.g. buying probabilities (Predictive Modeling). To optimize the coverage and composition of target groups according to business objectives, business rules are derived from these models (Optimization, Business Rules Generation). Thus, these optimized business rules make it possible e.g. to address only a specific group of customers with a certain action that is very likely to generate a positive profit margin.

Having contacted selected customers (Action) responses are captured by operational CRM-systems, closing the characteristic loop of campaign management (Englbrecht 2007, pp. 44-47). These customer responses are used to adapt the process steps and obtain the planning foundation for the subsequent action.

For instance, within Predictive Modeling the weights of regressor variables are fitted to the observed behavior, or even other types of predictive models are used (e.g. a neural net replacing a regression model). Adaptations to current changes in customer behavior are mandatory in other process steps as well, although the adaptation cycles are longer. For instance, within Action the optimal point in time for delivering e-mails is configured, within Data Generation ETL-cycles for loading customer response into the
DWH are reduced, within Data Preparation new variables are derived, or within Optimization a new control process following the next-best-activity concept is introduced. To improve the adaptation of business rules for campaign management according to current customer behavior, one option is to execute samplebased pre-tests which are carried out immediately before the actual campaign execution. According to the test results, the steps of Predictive Modeling, Optimization and Business Rules Generation are adapted to customer preferences directly before the campaign execution. The execution of an e-mail campaign promoting e.g. mobile accessories thus matches current customer behavior significantly better than when using last month's campaign responses as a basis. This presumes that the closed-loop process (Fig. 1) is fully completed within the short period between the pre-test and the campaign execution. Especially regarding the time and labor-consuming analytical tasks of Predictive Modeling, Optimization and Business Rules Generation, real-time technologies (Sect. 4) allow for necessary acceleration and efficiency improvements through automation.

At best, adaptation is refined from a non-recurring pre-test to a continuous real-time test and adaptation process: the campaign is not split into a (small) pre-test sample and a (large) main dispatch. Instead, a series of contact portions, so called tranches, is introduced which are executed sequentially. After each tranche the closed-loop process is carried out in real-time. This allows the current responses-just a few days or hours old-to influence the composition of the following tranches, and thereby the campaign itself. Current changes in customer responses are recorded and considered during the campaign execution (e.g. in the case of EPOQ, a software described by Martin 2006). Empirical tests of this process enhancement in the finance and mail order sector have led to remarkable increase of success in campaign management (EPOQ GmbH 2008; Osterholt 2005, p. 10).

\section{Right-Time in CRM-Processes}

The enhancement of campaign success through real-time adaptation demonstrates that the value of information in dynamic customer and market situations steadily decreases when action time increases. Action time is defined as the period between the occurrence of an event on customer-side and the corresponding reaction of the company. Fig. 2 depicts the latencies constituting the action time (Schelp 2006, pp. 426-430; Hackathorn 2004).

Data latency results from time lags as a result of event perception and the capture of changes in customer attributes in operational CRM-processes and the transmission to analytical CRM-systems, e.g. the DWH. Further latencies are induced by data preparation, transformation and analysis, as well as by decision and execution processes. The impact of the applied action constitutes the ultimate latency of the action time. As example, the impact of a postal direct mailing mostly results in a response weeks after the mailing. 


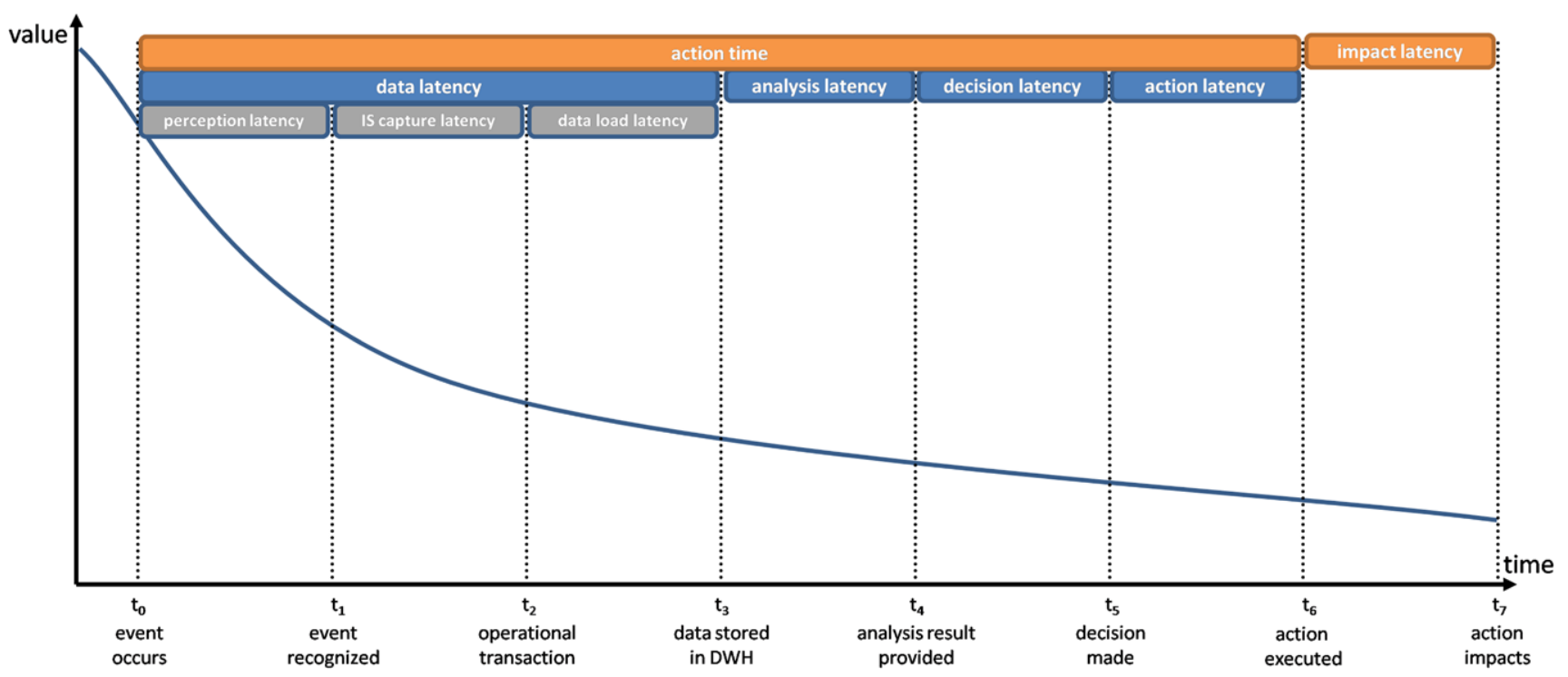

Fig. 2 Latencies in CRM

But not only the impact latency but also the internally induced latencies regarding event perception, data capture, transmission and analysis, and predictive model application must be reduced to take advantage of the real-time adaptation outlined in Sect. 3. In terms of data latency the design and direct linkup of communication channels to DWHsystems account for an action time reduction. Automated ETL-components decrease event perception and data capture as well as data load latencies. To scale down analysis latency, the analytical processes of the model development, model application, and business rules generation within Predictive Modeling, Optimization, und Business Rules Generation are automated as far as possible, avoiding time consuming manual interventions. The provision of analytical models as services within a serviceoriented business process design allows for a non-lagging integration of operational and analytical processes (Gluchowski et al. 2008, pp. 346-348).

Anticipated gains as well as investment and operating costs for hardware, software, and business process redesign which are necessary to reduce latencies have to be compared in a cost-benefit analysis (Hackathorn 2004). The optimal economic balance of latencies resulting from the consideration of this tradeoff is referred to as "right-time" (Gluchowski et al. 2008, p. 339). It is expected that the prediction quality of automatically developed models lags behind models developed by dedicated experts. This results in higher costs of misclassifications which have to be considered in the cost-benefit analysis of reducing latencies (especially regarding modeling and decision processes). Besides considering these trade-offs the right-time design of customer oriented business processes demands the choice of appropriate adaptation cycles in respect to involved process steps. For the adaptation of predictive models, very short cycles (weeks, days, or even hours) make sense, while reasonable cycles for adapting DWH data structures cover longer periods (months or years).

\section{Conclusion and Outlook}

Adaptive Right-time Technologies (ART) in CRM contain multiple approaches of process optimization. These allow for an optimal economic balance of latencies and a symbiotic integration of operational and analytical processes.

The advance of this integration will be in the focus of further progress. Besides general technological and organizational requirements (e.g. system architectures, hardware performance etc., and automation of formerly manual processes) the economically optimal application of ART in CRM-processes is the object of future research. As to the automated development and adaptation of predictive models, the "exploit/explore"-ratio is moved center stage of a permanent testing and learning process (Rokach et al. 2008, pp. 314-315). This involves finding the optimal ratio between contacts for exploiting existing customer knowledge (exploit) and contacts for gaining new customer insight (explore) automatically.

On the part of CRM-software providers an integration of analytical components into products supporting operational processes is already taking place. Further enhancements are expected regarding the automation of development and adaptation of predictive models and business rules.

\section{References}

Berry MJA, Linoff GS (2000) Mastering data mining. Wiley, New York

Englbrecht A (2007) Kundenwertorientiertes Kampagnen-Management im CRM. Kovač, Hamburg

EPOQ GmbH (2008) Outbound case study. PSD Banken Gruppe. http://www.epoq.de/ pdf/case-study-psd-bank.pdf. Accessed 2009-07-01

Gluchowski P, Gabriel R, Dittmar C (2008) Management support systeme und business intelligence - Computergestützte Informationssysteme für Fach- und Führungskräfte. Springer, Heidelberg

Hackathorn R (2004) The Bl watch: realtime to real-value. DM Review, January 2004. http://www.dmreview.com/issues/ 20040101/7913-1.html. Accessed 2009-0701

Hippner H, Wilde KD (2002) CRM - Ein Überblick. In: Helmke S, Dangelmaier W (eds) Effektives Customer Relationship Management. Gabler, Wiesbaden

Hippner H, Rentzmann R, Wilde KD (2004) Aufbau und Funktionalitäten von CRMSystemen. In: Hippner H, Wilde KD (eds) ITSysteme im CRM - Aufbau und Potenziale. Gabler, Wiesbaden

Martin W (2006) Dynamische Optimierung von Kundenkontakten in Echtzeit. http:// www.competence-site.de/downloads/e9/ 97/i file 28940/EPOQ_whitepaper_de_fin. pdf. Accessed 2009-07-01 
Michalewicz Z, Schmidt M, Michalewicz M, Chiriac C (2007) Adaptive business intelligence. Springer, Heidelberg

Osterholt B (2005) Closed Loop in Echtzeit. Database Marketing 2005(2):8-11
Rokach L, Naamani L, Shmilovici A (2008) Pessimistic cost-sensitive active learning of decision trees for profit maximizing targeting campaigns. Data Mining and Knowledge Discovery 17(2):283-316
Schelp J (2006) "Real"-time data warehousing und EAl. In: Chamoni P, Gluchowski $P$ (eds) Analytische Informationssysteme - Business Intelligence-Technologien und -Anwendungen. Springer, Heidelberg 